\title{
IOT Based Smart Energy Meter Design for Home with Energy Consumption Limit
}

\author{
M. Rupesh ${ }^{1}$, Dr.N.Anbu Selvan ${ }^{2}$ \\ \{Roopeshroop97@gmail.com ${ }^{1}$ anbu.1324@gmail.com ${ }^{2}$ \}
}

\begin{abstract}
UG Scholar ${ }^{1}$, , Department of Electrical and Electronics Engineering, Saveetha School of Engineering, Saveetha Institute of Medical And Technical Science, Chennai

Assistant Professor ${ }^{2}$, Department of Electrical and Electronics Engineering, Saveetha School of Engineering, Saveetha Institute of Medical And Technical Science, Chennai
\end{abstract}

\begin{abstract}
The Communication technology development is increased day by day. Due to the development of communication technology every products are manufactured with smart activities. From the past decade most of the electric devices executed automatically using remote control. Internet of Things (IoT) is used to connect the various devices easily with the help of sensors. All the connected devices are working automatically without any human interventions. The roles of human beings are only to manage and control the connected devices from remote location. Electric meters also using the concept of IoT. In this paper describes about smart meter device. The main purpose of this system is read the amount current consumption units automatically with the help of LED light calculate the amount and display the messages to the user's web site and user's smart phone. This system also issues the alert message to the user when the current consumption unit cross the limited level.
\end{abstract}

Keywords: Smart Energy Meter, Electric board, LED, IoT, GSM, Wi-Fi, webpage.

\section{Introduction}

Now the growth of population is increased day by day. Due to this reason the residential places and industries need large amount of current. Various systems are already introduced to save energy from residential electric meter devices. In traditional days, the energy meter device fit inside the users premises. The consumption rate was taken by human being and updated into the system. This system was extremely dependent on operator. The operator went to the users locations for collecting the information. It is the very difficult process. To avoid this condition the proposed system is used to measure current consumption rate automatically. This system is used to collect the current consumption value and provide the alert message to the user with the help of IoT. The IoT concept permits physical devices to be measure and managed vaguely across already available network connection, create a direct communication between the real world and computer system. The result of the IoT technique is getting accurate result and avail financial benefit. This technology has developed from it starting stage and currently using this concept. Electricity is important in everyone life. Without electricity the people cannot able live in this current world.

This proposed system is used to collect the data from the user's location and use this information for bill calculating process. The measure value will be stored on the server and it is used for amount calculation also. This system measures the current consumption units 
accurately. This system totally removes the human intervention. This proposed system display the real time current consumption data on the LCD screen. Wi-Fi modem can be used to check the consumed units and give threshold unit level via webpage.

The paper is divided into various parts. Section II describes same work available in existing study. Section III presented current system architecture. The new proposed system was practically implemented and tested and the offered results shown in section IV. At last section discussed about the conclusion of the proposed system.

\section{Literature Survey}

BirendrakumarSahani et al., explained about the traditional meter reading system. In existing meter reading system a human can come from electricity board and stand in front of the electric meter to measure the current consumption units. This is used for calculate electricity bill. The main disadvantage of this traditional system was the human go to the users location, measure the units consumed and handover the bill to the consumers. Based upon their calculation the users pay the amount. In sometime extra amount will be added with the electricity bill by human's mistake. To avoid this problem the authors constructed a new system using IoT and Arduino concept. In this proposed work Arduino controller was used. Because it uses less power and fast processing capability compared with other controllers. This proposed system was embedded with the existing system. GSM concept was used to send the messages to the user[1].

Mrs.Geetha.R M.E et al., says that in the existing system the electricity people directly went to the users location and note the meter readings. Based upon the value of unit consumed the electricity bill was created and give to the user. Here the authors proposed a new system to read the meter reading automatically by using Arduino controller. This system was providing the privilege to check the energy consumption and the bill amount using Wi-Fi module. This system will be reduce the human energy and prevent the machines from repair [2].

A.Subba Rao et al., provide a new architecture to measure and control the electric meters in residential places continuously. Finally they constructed a new system controlled from remote location. This proposed architecture can able to transfer the information to the server and send the SMS using GSM concept. This frame work has been implemented by using ARM processor controller with some set of sensor [3].

Amrita Singh et al, constructed new system for measure power usages. This system entirely avoids person interruption during the power measurement stage. It was constructed by using the new concept IoT. This technology is used to create the connection in physical objects with the help of various software and sensor devices. Using this IoT concept every devices are able to transfer the data between them. This smart meter is used to automatically read the electrical consumption from the users meter device and transfer the data to the server. Using this data the bill will be calculated and send to the user and the current readings will be displayed on the screen. This proposed system will be used to produce the accurate result and proper amount [4].

Mr. Samarth Pandit et al., explained about the various disadvantages of the existing meter reading system. This proposed system measure the current consumption rate automatically at small level. The main objective of this proposed system was reducing the power usages in 
various appliances. This project was implemented by using Arduino UNO micro controller and IoT techniques. If any critical conditions are measured this system automatically cut the power supply [5].

Pooja D Talwar et al., described about the monitor the power consumption in domestic places and calculate electricity bill with the help of current telecommunication technologies. The main aim of this system was to decrease the human resource in electrical department. The electricity bill was calculated in automatic manner and send directly to the consumers with the help of IoT. The electricity bill has seen anywhere from the world. All information sent by using IoT and stored in web server [6].

Saha, $\mathrm{S}$ et al., explained about grid techniques used in electric products. Smart electric meter is constructed by using advanced metering infrastructures. This new systems are extensively spread and organized to the newly connected network. Now power producing systems also affected by various attacks. The presented system was operated based on IoT using using Arduino controller [7].

Himanshu K. Patel, et al., construct and implement a new system used to avoid person intervention in electric meter reading and generating electric bill. The major benefit of this proposed system was avoid corruption in electric power usages and generating electric bill. This system is constructed by using GSM approach, Arduino controller combined with LDR sensor module and relay capability. Here the LDR sensor integrated with the LED light on the meter box tool and transfer the data to the microcontroller using GSM module. This system is also used to send the SMS to the concern users[8].

Anirudh Kumar et al., says that smart electric meters are talented in the direction of boost in energy competence. But the installation of this proposed system was very difficult compare with an existing traditional system. In this smart meter the LDR sensor was used to measure the LED blinking frequencies. Normally the number LED blinks directly proportional to the normal power stored in the traditional meter device. The sensed data from the LED blinker will be stored on the web server for future purpose [10].

S. Imran et al., developed a new electric meter using the concept of IoT. In this system LDR sensor is used to calculate the frequency of the LED blinks. According to the number of blinks the electric bill will be calculated. The microcontroller collect the data from the LDR sensor and display the result on the LCD screen connected with the controller [11].

Shaista Hassan Mir designed a advanced electric meter using Arduino micro controller and GSM technology. This smart meter is used to generate the electric bill automatically and send the bill to the user automatically via GSM modem [12].

F. Abate et al., says that the number of smart devices increase day by day. These smart devices are used to making everything as a smart working. It allows making the city as a smart city, home as the smart home etc. The smart meter consists of various hardware parts and software. The most of the parts in the smart meter are constructed by using chips that computes the attributed used to evaluate energy usage. Mostly the parts of smart meters are based on a chip that calculates the parameters needed to energy usage [13].

\section{Proposed Method}

This proposed smart meter is used to measure the energy consumption automatically and calculate the bill automatically with the help of IoT and GSM techniques. This system is developed by using Arudino microcontroller. All the devices are integrated with the micro 
controller. The following figure represents the actual architecture diagram of the proposed system. Here the energy consumption units measured from the user's location and calculate the bill. The generated bill send to the user smart phone through SMS service

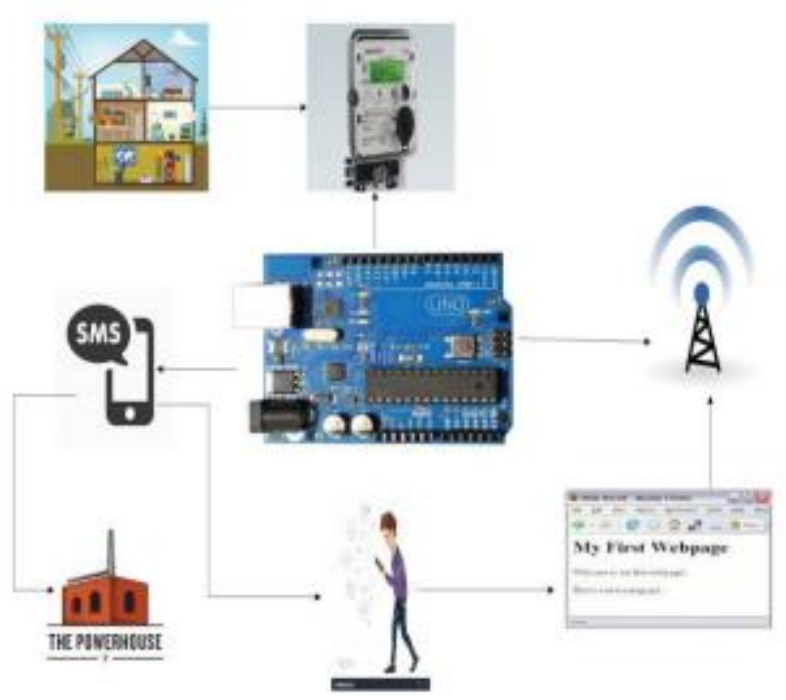

Fig 1 Architecture diagram of Proposed System

\section{Results And Discussions}

This proposed system is used to measure the electric current consumption automatically. The unit count will be based on number of blinks of LED light. The LED light is already available in the smart meter. The LDR sensor is connected with the LED light. Based upon the frequency of the LED blinks the unit of electric current will be calculated by the controller. After the calculation process the controller send the bill to the concern user. At the same time the bill will be updated on the user's web site using WiFi module also. If the user crosses the limited range the system will automatically produce the alert SMS message to the user's smart phone. This system is developed by using Arduino micro controller. The following figure 2 shows the flow diagram of proposed smart meter system. 


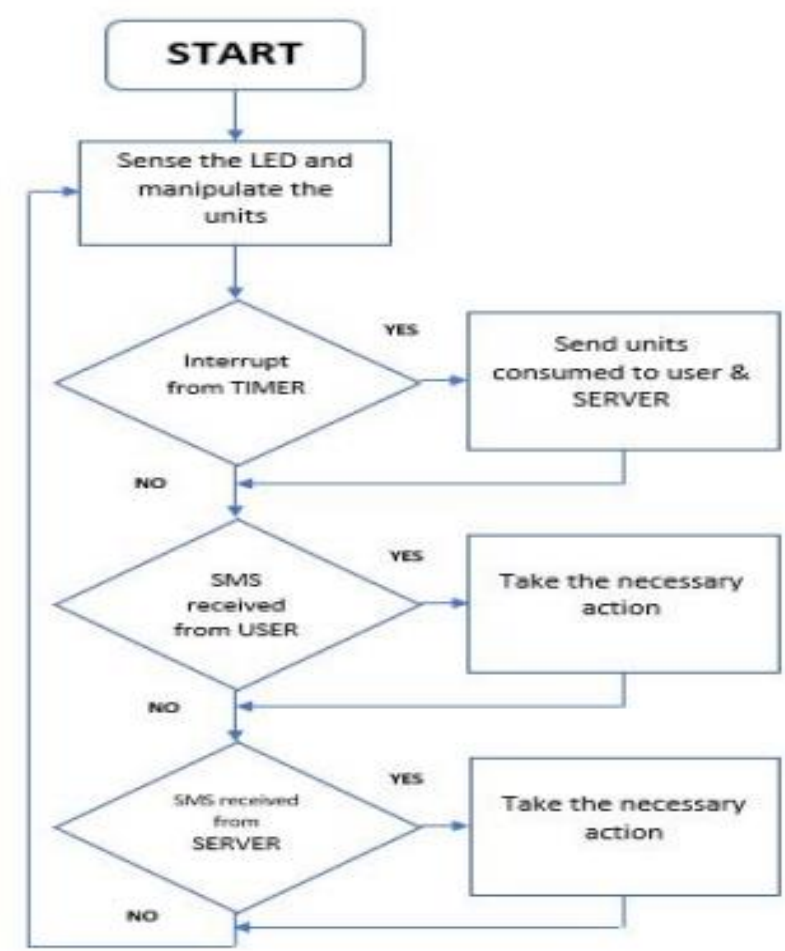

Fig 2 Flow Diagram of Proposed System.

The following screen shot shows the sample output of the proposed system. Based upon units consumed the amount will be calculated.

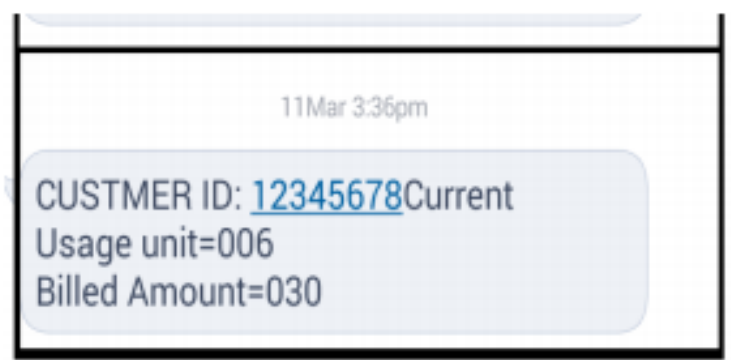

Fig 3 Output Screen 1

This proposed system also provides the alert message to the user if the consumed electric power cross the limit. The following figure 4 shows the alert and awareness message displayed to the user. 


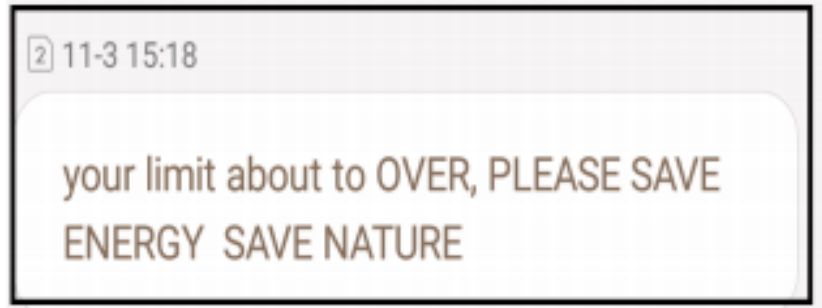

Fig 4 Output Screen 2

\section{Conclusion}

An advanced energy meters that measures electrical energy consumption in an accurate manner and also provides extra information as compared to a conventional energy meter. The main advantage of smart meter is it alerts us when our energy consumption crosses the actual limit by sending a message. These smart meters can measure the reading and send the information to the customers within small interval of time.

\section{References}

[1] BirendrakumarSahani, Tejashree Ravi, AkibjavedTamboli\&RanjeetPisal(2017)," IoT Based Smart Energy Meter", International Research Journal of Engineering and Technology (IRJET), Vol. 04, No. 04, ISSN: 2395-0072, pp. 96-102.

[2] Geetha.R ,Abhishek.D\&Rajalakshmi.G(2018), “Smart Energy Meter Using IoT “,International Journal of Recent Trends in Engineering \& Research (IJRTER) Conference on Electronics, Information and Communication Systems (CELICS'18), ISSN: 2455-1457, pp. 235-239.

[3] A.Subba Rao \& Sri VidyaGarige(2019), "IOT Based Smart Energy Meter Billing Monitoring and Controlling the Loads", International Journal of Innovative Technology and Exploring Engineering (IJITEE), ISSN: 2278-3075, Vol. 8, No. 4, pp. 340-344.

[4] Amrita Singh \& Ravi Gupta, "IoT based smart energy meter", International Journal of Advancement Research and Development, Vol. 3, No. 3, pp 328-331.

[5] Samarth Pandit ,SnehaMandhre\&MeghanaNichal(2017)", Smart Energy Meter using internet of Things (IoT) “, VJER-Vishwakarma Journal of Engineering Research, Vol. 1, No. 2, ISSN: 24568465, pp 222-229.

[6] Pooja D Talwar\& S B Kulkarni,” Iot Based Energy Meter Reading”, International of Journal Recent Trends in Eginerring and Research, pp.586-591

[7] Saha, S., Mondal, S., Saha, A \&Purkait, P. (2018). Design and Implementation of IoT Based Smart Energy Meter., 2018 IEEE Applied Signal Processing Conference (ASPCON), pp 19-23.

[8] Patel, H. K., Mody, T., \& Goyal, A. (2019), " Arduino Based Smart Energy Meter using GSM", 2019 4th International Conference on Internet of Things: Smart Innovation and Usages (IoT-SIU)

[9] Al-Ali, A. R., Landolsi, T., Hassan, M. H., Ezzeddine, M., Abdelsalam, M., \&Baseet, M. (2018), “ AnIoT-Based Smart Utility Meter", 2018 2nd International Conference on Smart Grid and Smart Cities (ICSGSC).

[10] Kumar, A., Thakur, S., \&Bhattacharjee, P. (2018), "Real Time Monitoring of AMR Enabled Energy Meter for AMI in Smart City - An IoT Application|, 2018 IEEE International Symposium on Smart Electronic Systems (iSES), pp 219-222. 
[11] S. Imran \& K. Prahlada Rao(2017), “ IOT BASED ELECTRICITY ENERGY METER READING THROUGH INTERNET”, International Journal of Technical Innovation in Modern Engineering \& Science (IJTIMES), ISSN: 2455-2585, Vol. 3, No.11, pp. 34-40.

[12] Shaista Hassan Mir, SahreenAshruf, Sameena, Yasmeen Bhat \& Nadeem Beigh(2019), "Review on Smart Electric Metering System Based on GSM/IOT", Asian Journal of Electrical Sciences, ISSN: 2249-6297, Vol. 8, No. 1, pp. 1-6.

[13] F. Abate, M. Carratù, C. Liguori\& M. Ferro(2018), "Smart Meter for the IoT".

[14] K. Anuradha\& S. Nirmala SugirthaRajini(2019), "Analysis of Machine Learning Algorithm in IOT Security Issues and Challenges", Jour of Adv Research in Dynamical \& Control Systems, Vol. 11, No. 9, pp. 1030-1034. 